\title{
Rechtsgeschichte
}

http://www.rg-rechtsgeschichte.de/rg7

$\operatorname{Rg} 2005$

$218-218$

Zitiervorschlag: Rechtsgeschichte Rg 7 (2005)

http://dx.doi.org/10.12946/rg07/218-218

\section{Karl-Heinz Lingens}

\section{Bomben-Werbung}




\section{Bomben-Werbung*}

Das flüchtige Blättern in den Waschzetteln endet jäh. Was stand da eben? "Historisch und komparativ angereichert, skizziert der Autor die Entwicklungstendenzen transatlantischer Sicherheit und Verteidigung, zeigt die integrationsbedingten Kontrolldefizite des Deutschen Bundestages auf und liefert einen Beitrag zur aktuellen Diskussion um die gesetzliche Ausgestaltung der parlamentarischen Beteiligung beim Streitkräfteeinsatz. «Die Zielgruppe eines Buches über die »Parlamentarische Kontrolle der internationalen Streitkräfteintegration « mag mit dieser Werbeattacke voll getroffen werden, der grammatische Kollateralschaden ist jedoch gewaltig. "Der Bezug des satzwertigen Partizips auf das entsprechende Glied im zugehörigen Satz muss eindeutig sein «, verlangt der Duden, »um Missverständnisse oder unfreiwillige Komik zu vermeiden." Der historisch und komparativ angereicherte Autor ist eine würdige Ergänzung des Beispiels »Mit Wein angefüllt, überreiche ich dem Jubilar diesen goldenen Becher «.

Apropos Wein: Nach den deutschen Rechtsvorschriften ist eine Anreicherung bei »Qualitätsweinen mit Prädikat " per definitionem ausgeschlossen. Es kann unterstellt werden, dass der Verfasser des Werbetextes weder derartige Vergleiche heraufbeschwören noch der Studie bescheinigen wollte, sie sei nur durch den $\mathrm{Zu}$ satz historischer und komparatistischer Elemente genießbar geworden. Er hätte auch Unrecht: Schmidt-Radefeldt behandelt in seiner Leipziger Habilitationsschrift kompetent und sprachlich einwandfrei die verfassungsrechtlichen Probleme, die der Einsatz deutscher Soldaten in multi- nationalen Korps und im Rahmen kollektiver Sicherheitssysteme im Hinblick auf die demokratische Legitimation und die parlamentarische Kontrolle der Befehlskette aufwirft. Dass sein Werk durch das deutsche Parlamentsbeteiligungsgesetz vom I 8. März 2005 eingeholt wurde, entwertet die lesenswerte Arbeit keineswegs.

Enttäuscht wird nur, wer bei Anreicherung in nahe liegender Weise Methoden der Kerntechnik assoziiert (» angereichertes Uran «) und daher ein Buch erwartet, das historische und vergleichende Aspekte in besonderem Maße berücksichtigt. Während Schmidt-Radefeldts kurzer europäischer Verfassungsvergleich zur Kompetenzverteilung zwischen Regierung und Parlament beim Streitkräfteeinsatz auf den Primärquellen beruht, sind die eingestreuten historischen Passagen generell aus zweiter oder gar dritter Hand (wenn, wie auffällig oft, die entsprechende Fußnote auf juristische Kommentarliteratur verweist). So zu verfahren ist durchaus legitim, sollte als Mindestanforderung aber eine Selbstverständlichkeit sein, die keiner Hervorhebung in der Werbung bedarf. Denn wie lässt sich ein solches Thema mit wissenschaftlichem Anspruch überhaupt anders abhandeln als unter Berücksichtigung der geschichtlichen und vergleichenden Aspekte? Die gehören zum Kern, sind Voraussetzung für Qualität und kein schmückendes Beiwerk, wie der Autor selbst beweist. Solange wesentliche Bestandteile als Anreicherung angepriesen werden, ist die Wissenschaft arm dran.

\footnotetext{
* Roman Schmidt-Radefeldt, Parlamentarische Kontrolle der internationalen Streitkräfteintegration (Schriften zum Völkerrecht, Bd. I 56), Berlin: Duncker \& Humblot 2005 , 322 S., ISBN 3-428-I I 349-7
} 